\title{
Comparison of effect-site concentration of remifentanil for tracheal intubation with the lightwand and laryngoscopy during propofol target-controlled infusion
}

\author{
Jin-Soo Kim, Dae-Hee Kim, Sang-Kee Min, Kyung-Mi Kim, and Jong-Yeop Kim \\ Department of Anesthesiology and Pain Medicine, Ajou University School of Medicine, Suwon, Korea
}

Background: Target-controlled infusion (TCI) of propofol and remifentanil can provide satisfactory intubating conditions without a neuromuscular blocking agent. We compared the effect-site concentration of remifentanil required for intubation with the lightwand and the Macintosh laryngoscope during propofol TCI without a neuromuscular blocking agent in adult patients.

Methods: Forty-nine patients were randomly assigned to the lightwand group ( $\mathrm{n}=25)$ or the direct laryngoscope group $(n=24)$. Anesthesia was induced by propofol TCI with an effect-site concentration of $5.4 \mu \mathrm{g} / \mathrm{ml}$. Two minutes after start of propofol TCI, remifentanil was administered at the predetermined effect-site concentration. The effectsite concentration of remifentanil was determined using Dixon's up-and-down method $(0.5 \mathrm{ng} / \mathrm{ml}$ as a step size). The first patient in each group was tested at $4.5 \mathrm{ng} / \mathrm{ml}$ of remifentanil. Tracheal intubation was performed $2 \mathrm{~min}$ after the start of remifentanil TCI. Acceptable intubation was defined as an excellent or good intubating conditions.

Results: Using a modified Dixon's up and down method, the EC50 \pm SD of remifentanil in the lightwand and laryngoscope groups was $4.75 \pm 0.71 \mathrm{ng} / \mathrm{ml}$ and $5.08 \pm 0.52 \mathrm{ng} / \mathrm{ml}$, respectively; there was no statistically significant difference between the groups $(\mathrm{P}=0.373)$.

Conclusions: The effect-site concentration of remifentanil for acceptable intubation with the lightwand and Macintosh laryngoscope in $50 \%$ of adults did not differ during propofol TCI without a neuromuscular blocking agent. (Korean J Anesthesiol 2011; 60: 393-397)

Key Words: Intubation, Lightwand, Propofol, Remifentanil, Target-controlled infusion.

Received: September 27, 2010. Revised: 1st, November 18, 2010; 2nd, November 25, 2010. Accepted: November 25, 2010.

Corresponding author: Jong-Yeop Kim, M.D., Department of Anesthesiology and Pain Medicine, Ajou University School of Medicine, San 5, Wonchon-dong, Yeongtong-gu, Suwon 443-721, Korea. Tel: 82-31-219-5574, Fax: 82-31-219-5579, E-mail: kjyeop@ajou.ac.kr

(c) This is an open-access article distributed under the terms of the Creative Commons Attribution Non-Commercial License (http:// creativecommons.org/licenses/by-nc/3.0/), which permits unrestricted non-commercial use, distribution, and reproduction in any medium, provided the original work is properly cited. 


\section{Introduction}

As an alternative to direct laryngoscopy, the lightwand is an effective and safe intubation device. Theoretically, the lightwand technique may cause less adrenergic stimulation because the elevation of the epiglottis by the laryngoscope blade is not required. Previous studies have demonstrated that use of the lightwand for intubation of the tracheal tube causes a similar or lesser degree of a hemodynamic change when compared direct laryngoscopy [1-3]. Accordingly, the depth of anesthesia required to achieve ideal conditions for tracheal intubation using the lightwand may be different. Propofol and remifentanil have been shown to provide good intubating conditions without the use of neuromuscular blocking drugs $[4,5]$. To date, there have been no reports on the dose of remifentanil for acceptable tracheal intubation with the lightwand during propofol induction. Therefore, we compared the effect-site concentration of remifentanil concentration required for intubation with the lightwand and the Macintosh laryngoscope during propofol TCI without a neuromuscular blocking agent in adult patients.

\section{Materials and Methods}

This study was approved by the institutional review board, and written informed consent for the study was obtained from all patients. We enrolled ASA I or II patients, aged 18-60 years, undergoing general anesthesia for nasal bone fracture surgery. Patients with a history of reactive airway disease, cardiovascular disease and suspected airway difficulty were excluded from the study. No premedication was administered prior to surgery. For drug injection, a 20-gauge cannula was inserted into the forearm or dorsum of the hand, and connected to a T-connector prior to arrival in the operating room. Upon entry to the operating room, all patients were monitored with an electrocardiogram, a pulse oximeter, and noninvasive blood pressure. Using a computer-generated randomization table, patients were randomly assigned to the lightwand group or the direct laryngoscope group. Following injection of $30 \mathrm{mg}$ lidocaine, anesthesia was induced with propofol TCI with an effect-site concentration of $5.4 \mu \mathrm{g} / \mathrm{ml}$. Two minutes after start of propofol TCI (i.e. when the predicted concentration of propofol between plasma and effect-site was reached a pseudoequilibrium state), remifentanil was administered through a TCI device at the predetermined effect-site concentration. A commercially available two-channel TCI pump (Orchestra ${ }^{\circledR}$, Fresenius Vial, Brezins, France) was used for effect-site TCI of propofol and remifentanil. The pharmacokinetic models used for calculation of target effect-site concentrations for propofol and remifentanil were described previously by Marsh and colleagues [6] and Minto and colleagues [7], respectively. The $k_{\mathrm{e} 0}$ value used for propofol was 1.21/min [8]. Infusions of propofol and remifentanil were prepared in $50 \mathrm{ml}$ syringes using $2 \%$ propofol and $2 \mathrm{mg}$ of remifentanil (diluted with normal saline to make a $40 \mu \mathrm{g} / \mathrm{ml}$ solution). Tracheal intubation was performed 2 min after the start of remifentanil TCI (when the predicted concentration of remifentanil between plasma and effect-site was reached a pseudo-equilibrium state). Tracheal intubations were carried out using either a Macintosh laryngoscope or a lightwand (Surch-Lite ${ }^{\mathrm{TM}}$, Aaron Medical Industries, St. Petersburg, FL). Endotracheal tubes with an internal diameter of $7.0 \mathrm{~mm}$ were used for female patients and tubes with an internal diameter of $8.0 \mathrm{~mm}$ were used for male patients.

The effect-site concentration of remifentanil for each patient was determined by the response of the previously tested patient using a modified Dixon's up-and-down method (0.5 ng/ $\mathrm{ml}$ as a step size) [9]. The first patient was tested at an effectsite concentration of remifentanil $4.5 \mathrm{ng} / \mathrm{ml}$. This was a target concentration close to the predicted remifentanil concentration at which there was a $50 \%$ probability of acceptable tracheal intubation (EC50) using a Macintosh laryngoscope [10]. If intubation was unacceptable, the target effect-site concentration of remifentanil for the next patient was increased by $0.5 \mathrm{ng} / \mathrm{ml}$. If acceptable, it was then decreased by $0.5 \mathrm{ng} / \mathrm{ml}$. Intubating conditions were evaluated according to a scoring system described by Viby-Mogensen [11] and are summarized in Table 1. However, vocal cord variables were excluded in the lightwand group. Acceptable intubation was defined as excellent or good intubating conditions. The anesthesiologist who performed the intubations and who assessed the intubating conditions was unaware of the effect-site concentration of remifentanil. If intubation failed due to strong movement by the patient, inadequate jaw relaxation, or closed vocal cords, target concentration of propofol and remifentanil increased to 6 to 8 $\mu \mathrm{g} / \mathrm{ml}$ and 6 to $8 \mathrm{ng} / \mathrm{ml}$, respectively. Thereafter, intubation was attempted. Clinically significant hypotension and bradycardia were defined as a mean arterial pressure (MAP) of $<55$ $\mathrm{mmHg}$ and a heart rate (HR) of $<45$ beats/min, respectively.

Table 1. Assessment of Intubation Conditions

\begin{tabular}{|c|c|c|c|}
\hline \multirow{3}{*}{ Variables } & \multicolumn{3}{|c|}{ Intubating conditions } \\
\hline & \multicolumn{2}{|c|}{ Acceptable } & \multirow{2}{*}{$\frac{\text { Unacceptable }}{\text { Poor }}$} \\
\hline & Excellent & Good & \\
\hline $\begin{array}{l}\text { Ease of laryngoscopy } \\
\text { or jaw relaxation }\end{array}$ & Easy & Fair & Difficult \\
\hline Vocal cord position & Abducted & Intermediate & Closed \\
\hline Vocal cord movement & None & Moving & Closing \\
\hline Airway reaction (coughing) & None & Diaphragm & Sustained \\
\hline Movement of the limbs & None & Slight & Vigorous \\
\hline
\end{tabular}

Excellent: all criteria are excellent. Good: all criteria are either excellent or good. Poor: presence of a single criterion listed under 'Poor'. 
These conditions were treated with atropine or ephedrine where appropriate. Laryngospasm was treated with increased propofol concentration and $0.3 \mathrm{mg} / \mathrm{kg}$ of rocuronium. MAP, HR, and $\mathrm{SpO}_{2}$ were recorded at anesthetic induction, 2 min after propofol infusion, before and $1 \mathrm{~min}$ after intubation. Time to loss of consciousness (LOC) and time to tracheal intubation were also measured. Time to intubation was defined as the interval between opening of the mouth and inflation of the endotracheal cuff.

This study ended when data from six independent pairs of patients with acceptable/unacceptable intubating conditions were collected in each group. Statistical analyses were performed using SPSS 13.0 for windows (SPSS Inc, Chicago, IL, USA). Data are expressed as mean \pm SD or number of patients. The EC50 of remifentanil which enabled acceptable tracheal intubation was determined by calculation of the average of the midpoint dose of all independent pairs of patients after six crossover points were obtained in each group.

Patient characteristics and induction profiles were compared using a Student's t-test. Changes in hemodynamic data between the groups were compared by repeated measures ANOVA. Changes between time points within the group were analyzed using univariate analysis of variance (ANOVA) followed by least significant difference (LSD) post hoc test. A P value of $<0.05$ was considered significant.

Table 2. Patient Characteristics

\begin{tabular}{lccc}
\hline & $\begin{array}{c}\text { Lightwand } \\
(\mathrm{n}=25)\end{array}$ & $\begin{array}{c}\text { Laryngosocpy } \\
(\mathrm{n}=24)\end{array}$ & P value \\
\hline Sex (M/F) & $21 / 4$ & $22 / 2$ & 0.413 \\
Age (yr) & $33.3 \pm 10.1$ & $31.3 \pm 10.0$ & 0.484 \\
Weight (kg) & $66.0 \pm 9.8$ & $68.0 \pm 12.8$ & 0.546 \\
Height (cm) & $170.8 \pm 7.7$ & $173.9 \pm 8.5$ & 0.205 \\
ASA class (I/II) & $24 / 1$ & $21 / 3$ & 0.277 \\
Time to LOC (s) & $67.2 \pm 25.0$ & $59.8 \pm 19.8$ & 0.258 \\
Time to intubation (s) & $28.8 \pm 7.7$ & $24.0 \pm 6.7^{*}$ & 0.025 \\
Total anesthesia time (min) & $28.0 \pm 3.8$ & $25.8 \pm 3.8$ & 0.053 \\
\hline
\end{tabular}

Values represent mean \pm SD or number of patients. LOC: loss of consciousness. ${ }^{*} \mathrm{P}<0.05$ compared with the lightwand group.

\section{Results}

Forty-nine patients were enrolled in this study. No significant differences in patient characteristics were observed between the two groups (Table 2). However, intubation time was significantly longer in the lightwand group than in the laryngoscope group (Table 2). Intubating conditions were good or excellent (i.e. acceptable intubation) in $12 / 25$ patients in the lightwand group and 12/24 patients in the laryngoscope group (Table 3 ). Table 4 lists hemodynamic data from patients with acceptable intubation during induction of anesthesia. The differences in MAP and HR over time were not statistically significant between the groups ( $\mathrm{P}=0.510,0.852$, respectively). Compared to the baseline value in both groups, MAP showed a significant decrease after anesthetic induction. Compared to the baseline value in both groups, HR showed no significant change during the induction of anesthesia. Fig. 1 shows the sequences of effect-site concentration of remifentanil for acceptable and unacceptable tracheal intubation in the two groups. Using Dixon's up and down method, the EC50 \pm SD of remifentanil in the lightwand and laryngoscope groups was $4.75 \pm 0.71 \mathrm{ng} /$ $\mathrm{ml}$ and $5.08 \pm 0.52 \mathrm{ng} / \mathrm{ml}$, respectively; there was no significant

Table 3. Intubation Conditions

\begin{tabular}{lcc}
\hline & $\begin{array}{c}\text { Lightwand } \\
(\mathrm{n}=25)\end{array}$ & $\begin{array}{c}\text { Laryngosocpy } \\
(\mathrm{n}=24)\end{array}$ \\
\hline Acceptable & & \\
$\quad$ Total & 12 & 12 \\
Excellent & 2 & 3 \\
$\quad$ Good & 10 & 9 \\
Unacceptable & & \\
$\quad$ Total & 13 & 12 \\
Succeeded & 13 & 10 \\
$\quad$ Failed & 0 & 2 \\
Cause of failure & & \\
$\quad$ Difficulty of jaw relaxation & 2 & 3 \\
Closed vocal cord & NA & 1 \\
Airway reaction (coughing) & 12 & 7 \\
$\quad$ Vigorous limb movements & 5 & 3
\end{tabular}

$\overline{\text { Values represent the number of patients. There were no significant }}$ differences between the groups.

Table 4. Mean Arterial Pressure (MAP) and Heart Rate (HR) during Anesthesia Induction in Acceptable Intubation Patients

\begin{tabular}{cccccc}
\hline Group & T0 & T1 & T3 & T4 & P value \\
\hline MAP (mmHg) & & & & & 0.510 \\
Lightwand & $93.9 \pm 10.9$ & $77.7 \pm 8.5^{*}$ & $72.6 \pm 10.5^{*}$ & $75.0 \pm 12.7^{*}$ & \\
Laryngoscopy & $94.2 \pm 12.7$ & $80.8 \pm 11.8^{*}$ & $76.4 \pm 12.6^{*}$ & $78.3 \pm 13.1^{*}$ & 0.852 \\
HR (beats/min) & & & & $70.1 \pm 13.2$ & \\
Lightwand & $68.8 \pm 15.5$ & $66.5 \pm 9.8$ & $62.7 \pm 7.7$ & $65.3 \pm 12.0$ & \\
Laryngoscopy & $72.0 \pm 10.2$ & $69.9 \pm 10.9$ & $63.7 \pm 8.1$ & & \\
\hline
\end{tabular}

Values represent mean \pm SD. T0: baseline, T1: 2 min after propofol infusion, T3: before intubation. T4: 1 min after intubation. There were no significant differences in MAP and HR over time between the groups. $* \mathrm{P}<0.05$ compared with baseline value. 
A

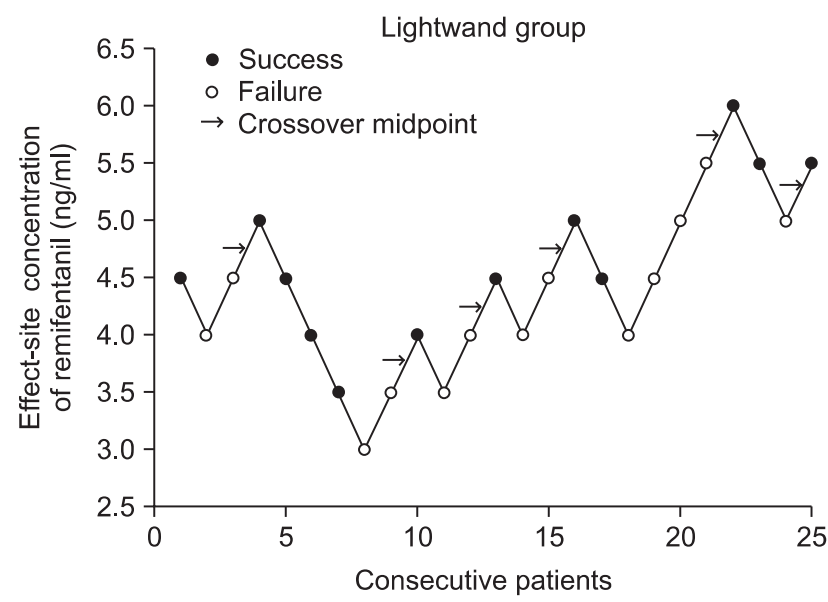

B

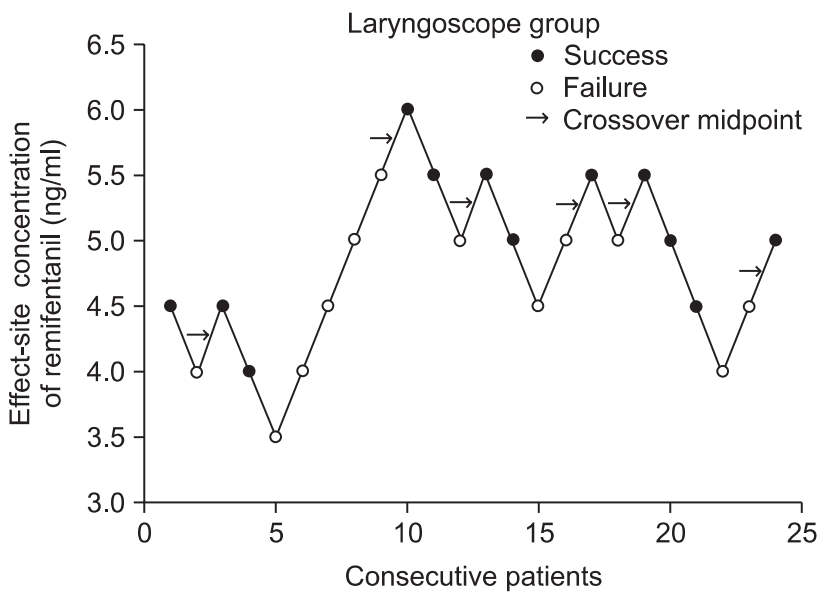

Fig. 1. Responses of 25 (lightwand, A) and 24 (laryngoscope, B) consecutive patients where tracheal intubation was attempted and the effectsite concentration of remifentanil. The EC50 of remifentanil in the lightwand group and the laryngoscope group was $4.75 \pm 0.71 \mathrm{ng} / \mathrm{ml}$ and 5.08 $\pm 0.52 \mathrm{ng} / \mathrm{ml}$, respectively.

difference between the groups $(\mathrm{P}=0.373)$. There were also no adverse respiratory events, such as laryngospasm, and $\mathrm{SpO}_{2}$ remained above $90 \%$ in all patients. None of the acceptable intubation patients suffered clinically significant bradycardia or hypotension.

\section{Discussion}

This study demonstrated that the effect-site concentration of remifentanil for acceptable intubation conditions using the lightwand and the Macintosh laryngoscope was $4.75 \pm 0.71 \mathrm{ng} /$ $\mathrm{ml}$ and $5.08 \pm 0.52 \mathrm{ng} / \mathrm{ml}$, respectively, in $50 \%$ of adults during propofol TCI at an effect-site concentration of $5.4 \mu \mathrm{g} / \mathrm{ml}$ without a neuromuscular blocking agent; there was no statistical difference between the groups.

The lightwand technique does not require that the mouth is wide open or that the epiglottis is elevated, or brought forward and lifted upward by the laryngoscope. In comparison with the use of the laryngoscope, the lightwand, which does not require a laryngoscope to elevate the epiglottis, should attenuate the airway reflexes. We assumed that intubation with the lightwand may be less stimulating, and that the dose of remifentanil required for lightwand intubation without neuromuscular blockade might be decreased. However, our results have shown that the EC50 of remifentanil for the lightwand and the laryngoscopic intubation was $4.75 \pm 0.71 \mathrm{ng} / \mathrm{ml}$ and 5.08 $\pm 0.52 \mathrm{ng} / \mathrm{ml}$, respectively, during propofol $\mathrm{TCI}$, indicating there was no strong evidence that the target concentrations of remifentanil for clinically acceptable intubation conditions differed based on the techniques used for intubation. In this study, the overall assessment of all variables suggest that coughing might be the main reason for failed intubation. This result implies that tracheal stimulus, and not stimuli to the oropharyngeal structures, is the primary cause of a stress response during tracheal intubation. In addition, a previous study reported that target remifentanil concentrations required for adequate intubating conditions did not differ between the Macintosh laryngoscope and the Glidescope [10].

In our study, there were no differences in hemodynamic changes between use of the lightwand technique and Macintosh laryngoscopy after tracheal intubation. These results are consistent with those of previous studies, which revealed similar hemodynamic responses between the techniques $[3,12,13]$. Hirabayashi et al. [3] reported that maximum MAP changes and HR changes were similar between the lightwand technique and direct laryngoscopy during and after tracheal intubation. Moreover, Takahashi et al. [12] demonstrated that the magnitude of hemodynamic changes associated with tracheal intubation with the lightwand (Trachlight) is almost the same as that which occurs with the direct laryngoscope. And they suggested hemodynamic changes are likely to occur because of direct tracheal irritation rather than direct stimulation of the larynx. Lastly, Montes et al. [13] have also shown that the lightwand technique does not reduce the hemodynamic response compared to standard direct-vision laryngoscopic intubation in patients with coronary artery disease. In contrast, Nishigawa et al. [1] reported that lightwand intubation produces a smaller increase in systolic blood pressure after tracheal intubation than with Macintosh laryngoscopic intubation in normotensive patients; however, in hypertensive patients, there were no differences in hemodynamic changes between the two techniques. Another comparative study showed that 
the lightwand attenuated the hemodynamic stress response to tracheal intubation when compared with the Macintosh laryngoscope in hypertensive, but not in normotensive patients [2]. Collectively, these conflicting results are likely related to differences in intubation techniques, in anesthetic regimen, and the method of recording hemodynamic variables.

Propofol TCI and adjuvant remifentanil have been shown to provide acceptable intubation conditions for tracheal intubation in adults without the use of a neuromuscular blocking agent $[10,14]$. Ithnin et al. [10] reported that the EC50 of remifentanil required for optimal tracheal intubating conditions was 4.41 $\mathrm{ng} / \mathrm{ml}$ when the propofol TCI effect-site concentration was $3.0 \mu \mathrm{g} / \mathrm{ml}$. These results were comparable to findings from our study. The EC50 of remifentanil in our study using Macintosh laryngoscopy intubation was $5.08 \pm 0.52 \mathrm{ng} / \mathrm{ml}$ during propofol TCI at an effect-site concentration of $5.4 \mu \mathrm{g} / \mathrm{ml}$. Since Smith et al. [15] have reported that the propofol blood concentration at which $95 \%$ of patients did not respond to verbal command was $5.4 \mu \mathrm{g} / \mathrm{ml}$, we selected this concentration of propofol for the induction of anesthesia. When propofol is administrated at a target effect-site concentration of $5.4 \mu \mathrm{g} / \mathrm{ml}$ using the integrated Marsh model, a pseudo-equilibrium state between plasma and effect-site is reached approximately $1.6 \mathrm{~min}$ after the start of TCI.

Tracheal intubation without neuromuscular blocking drugs may be used in cases where tracheal intubation is necessary but prolonged muscle relaxation is not, such as in short surgical procedures. We enrolled patients with nasal bone fractures, and total anesthetic time in our study was less than $30 \mathrm{~min}$. However, use of neuromuscular blocking drugs for tracheal intubation diminishes the incidence of adverse postoperative upper airway symptoms, results in better intubation conditions, and reduces the rate of adverse hemodynamic events [16]. In addition, avoidance of neuromuscular blocking drugs may increase the risk of difficult tracheal intubation [17]. Therefore, a more careful approach is needed for neuromuscular blocking agent-free intubation.

In conclusion, the predicted effect-site concentration of remifentanil for acceptable intubation with the lightwand in $50 \%$ of adults was $4.75 \mathrm{ng} / \mathrm{ml}$, when a propofol TCI of $5.4 \mu \mathrm{g} / \mathrm{ml}$ was used without a neuromuscular blocking agent. Concentrations of remifentanil for acceptable intubation with the lightwand and direct laryngoscopy did not differ.

\section{References}

1. Nishikawa K, Omote K, Kawana S, Namiki A. A comparison of hemodynamic changes after endotracheal intubation by using the lightwand device and the laryngoscope in normotensive and hypertensive patients. Anesth Analg 2000; 90: 1203-7.

2. Kihara S, Brimacombe J, Yaguchi Y, Watanabe S, Taguchi N, Komat- suzaki T. Hemodynamic responses among three tracheal intubation devices in normotensive and hypertensive patients. Anesth Analg 2003; 96: 890-5.

3. Hirabayashi Y, Hiruta M, Kawakami T, Inoue S, Fukuda H, Saitoh $\mathrm{K}$, et al. Effects of lightwand (Trachlight) compared with direct laryngoscopy on circulatory responses to tracheal intubation. Br J Anaesth 1998; 81: 253-5.

4. Stevens JB, Wheatley L. Tracheal intubation in ambulatory surgery patients: using remifentanil and propofol without muscle relaxants. Anesth Analg 1998; 86: 45-9.

5. Alexander R, Olufolabi AJ, Booth J, El-Moalem HE, Glass PS. Dosing study of remifentanil and propofol for tracheal intubation without the use of muscle relaxants. Anaesthesia 1999; 54: 1037-40.

6. Marsh B, White M, Morton N, Kenny GN. Pharmacokinetic model driven infusion of propofol in children. Br J Anaesth 1991; 67: 41-8.

7. Minto CF, Schnider TW, Egan TD, Youngs E, Lemmens HJ, Gambus $\mathrm{PL}$, et al. Influence of age and gender on the pharmacokinetics and pharmacodynamics of remifentanil. I. Model development. Anesthesiology 1997; 86: 10-23.

8. Struys MM, De Smet T, Depoorter B, Versichelen LF, Mortier EP, Dumortier FJ, et al. Comparison of plasma compartment versus two methods for effect compartment--controlled target-controlled infusion for propofol. Anesthesiology 2000; 92: 399-406.

9. Dixon WJ. Staircase bioassay: the up-and-down method. Neurosci Biobehav Rev 1991; 15: 47-50.

10. Ithnin F, Lim Y, Shah M, Shen L, Sia AT. Tracheal intubating conditions using propofol and remifentanil target-controlled infusion: a comparison of remifentanil EC50 for Glidescope and Macintosh. Eur J Anaesthesiol 2009; 26: 223-8.

11. Viby-Mogensen J, Engbaek J, Eriksson LI, Gramstad L, Jensen E, Jensen FS, et al. Good clinical research practice (GCRP) in pharmacodynamic studies of neuromuscular blocking agents. Acta Anaesthesiol Scand 1996; 40: 59-74.

12. Takahashi S, Mizutani T, Miyabe M, Toyooka H. Hemodynamic responses to tracheal intubation with laryngoscope versus lightwand intubating device (Trachlight) in adults with normal airway. Anesth Analg 2002; 95: 480-4.

13. Montes FR, Giraldo JC, Betancur LA, Rincón JD, Rincón IE, Vanegas MV, et al. Endotracheal intubation with a lightwand or a laryngoscope results in similar hemodynamic variations in patients with coronary artery disease. Can J Anaesth 2003; 50: 824-8.

14. Troy AM, Huthinson RC, Easy WR, Kenney GN. Tracheal intubating conditions using propofol and remifentanil target-controlled infusions. Anaesthesia 2002; 57: 1204-7.

15. Smith C, McEwan AI, Jhaveri R, Wilkinson M, Goodman D, Smith LR, et al. The interaction of fentanyl on the Cp50 of propofol for loss of consciousness and skin incision. Anesthesiology 1994; 81: 820-8.

16. Combes X, Andriamifidy L, Dufresne E, Suen P, Sauvat S, Scherrer E, et al. Comparison of two induction regimens using or not using muscle relaxant: impact on postoperative upper airway discomfort. Br J Anaesth 2007; 99: 276-81.

17. Lundstrøm LH, Møller AM, Rosenstock C, Astrup G, Gätke MR, Wetterslev J. Avoidance of neuromuscular blocking agents may increase the risk of difficult tracheal intubation: a cohort study of 103,812 consecutive adult patients recorded in the Danish Anesthesia Database. Br J Anaesth 2009; 103: 283-90. 